\title{
ANNOTATIONS
}

\section{Text Illustrations}

In a journal such as ours text illustrations play a very important part. We willingly admit that our contributors have sometimes been justified in their complaints as to the quality of the reproduction, more especially of microphotographs. The Editorial Committee have devoted considerable thought to this question. There are obviously only two methods whereby an improvement could be effected. The first is the use of a more highly polished paper. The objections to this, however, would in our opinion outweigh the advantages. The glare from the surface and the added weight make any such journal uncomfortable to read. The second possibility is the greater use of plate paper. The objections to this are two: taking the illustrations away from the context renders reference to them less easy, and the binding of the volume is rendered more costly, as unless plates are properly " guarded" in, they soon part company from the volume; moreover the volume so made up would be much more bulky and weighty.

\section{The Prevention of Blindness}

An infernational association to aid in the prevention of blindness was constituted at the recent congress in Holland. The headquarters of the association will be in Paris, and the following have been chosen as the Executive Committee : President, Professor de Lapersonne, Paris; Vice-President, Dr. Park Lewis, United States; Secretary, Dr. Humbert; Treasurer, M. Demarchy; Members, Professor van der Hoeve (Holland), Professor de Grosz (Hungary), Professor Axenfeld (Germany), Professor Marquez (Spain), Professor Trantas (Greece), Mr. Bernard Cridland (England), Professor Maggiore (Italy), Dr. Isahara (Japan), and Dr. Szymanski (Poland). Two seats have been reserved for Central and South America. 